\title{
ARTICLE
}

Animal Models

\section{Peripancreatic adipose tissue protects against high-fat-diet-induced hepatic steatosis and insulin resistance in mice}

\author{
Belén Chanclón ${ }^{1} \cdot$ Yanling $\mathrm{Wu}^{1} \cdot$ Milica Vujičić $\mathbb{1}^{1} \cdot$ Marco Bauzá-Thorbrügge ${ }^{1}$ - Elin Banke ${ }^{1}$ Peter Micallef ${ }^{1}$.

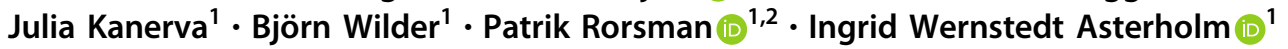

Received: 4 December 2019 / Revised: 27 July 2020 / Accepted: 15 August 2020 / Published online: 25 August 2020

(c) The Author(s), under exclusive licence to Springer Nature Limited 2020. This article is published with open access

\begin{abstract}
Background/objectives Visceral adiposity is associated with increased diabetes risk, while expansion of subcutaneous adipose tissue may be protective. However, the visceral compartment contains different fat depots. Peripancreatic adipose tissue (PAT) is an understudied visceral fat depot. Here, we aimed to define PAT functionality in lean and high-fat-diet (HFD)-induced obese mice.

Subjects/methods Four adipose tissue depots (inguinal, mesenteric, gonadal, and peripancreatic adipose tissue) from chowand HFD-fed male mice were compared with respect to adipocyte size ( $n=4-5 /$ group), cellular composition (FACS analysis, $n=5-6 /$ group), lipogenesis and lipolysis ( $n=3$ /group), and gene expression ( $n=6-10 /$ group). Radioactive tracers were used to compare lipid and glucose metabolism between these four fat depots in vivo ( $n=5-11 /$ group). To determine the role of PAT in obesity-associated metabolic disturbances, PAT was surgically removed prior to challenging the mice with HFD. PAT-ectomized mice were compared to sham controls with respect to glucose tolerance, basal and glucosestimulated insulin levels, hepatic and pancreatic steatosis, and gene expression ( $n=8-10 /$ group).

Results We found that PAT is a tiny fat depot ( $0.2 \%$ of the total fat mass) containing relatively small adipocytes and many "non-adipocytes" such as leukocytes and fibroblasts. PAT was distinguished from the other fat depots by increased glucose uptake and increased fatty acid oxidation in both lean and obese mice. Moreover, PAT was the only fat depot where the tissue weight correlated positively with liver weight in obese mice $(R=0.65 ; p=0.009)$. Surgical removal of PAT followed by 16 -week HFD feeding was associated with aggravated hepatic steatosis $(p=0.008)$ and higher basal $(p<0.05)$ and glucose-stimulated insulin levels $(p<0.01)$. PAT removal also led to enlarged pancreatic islets and increased pancreatic expression of markers of glucose-stimulated insulin secretion and islet development $(p<0.05)$.

Conclusions PAT is a small metabolically highly active fat depot that plays a previously unrecognized role in the pathogenesis of hepatic steatosis and insulin resistance in advanced obesity.
\end{abstract}

Supplementary information The online version of this article (https:// doi.org/10.1038/s41366-020-00657-6) contains supplementary material, which is available to authorized users.

Ingrid Wernstedt Asterholm

IWA@neuro.gu.se

1 Department of Physiology (Metabolic Physiology Research Unit), Institute of Neuroscience and Physiology, Sahlgrenska Academy, University of Gothenburg, Box 432, SE405 30

Gothenburg, Sweden

2 Oxford Centre for Diabetes, Endocrinology and Metabolism, Radcliffe Department of Medicine, University of Oxford, Oxford OX4 7LE, UK

\section{Introduction}

Proper storage of excess nutrients in adipose tissue during weight gain protects against the deleterious ectopic lipid deposition in non-adipose tissues. Typically, mouse models with a high capacity for hyperplastic subcutaneous adipose tissue expansion are protected against ectopic lipid deposition and its associated metabolic disturbances $[1,2]$. In contrast, increased visceral adiposity is a predictor of metabolic syndrome and insulin resistance [3-7]. Consequently, subcutaneous adipose tissue is regarded as "good fat" while visceral adipose tissue as "bad fat." In line with this assumption, partial lipectomy of visceral fat improved the metabolic profile [3], and transplantation of gonadal fat accelerated atherogenesis in apolipoprotein E-deficient 
A)

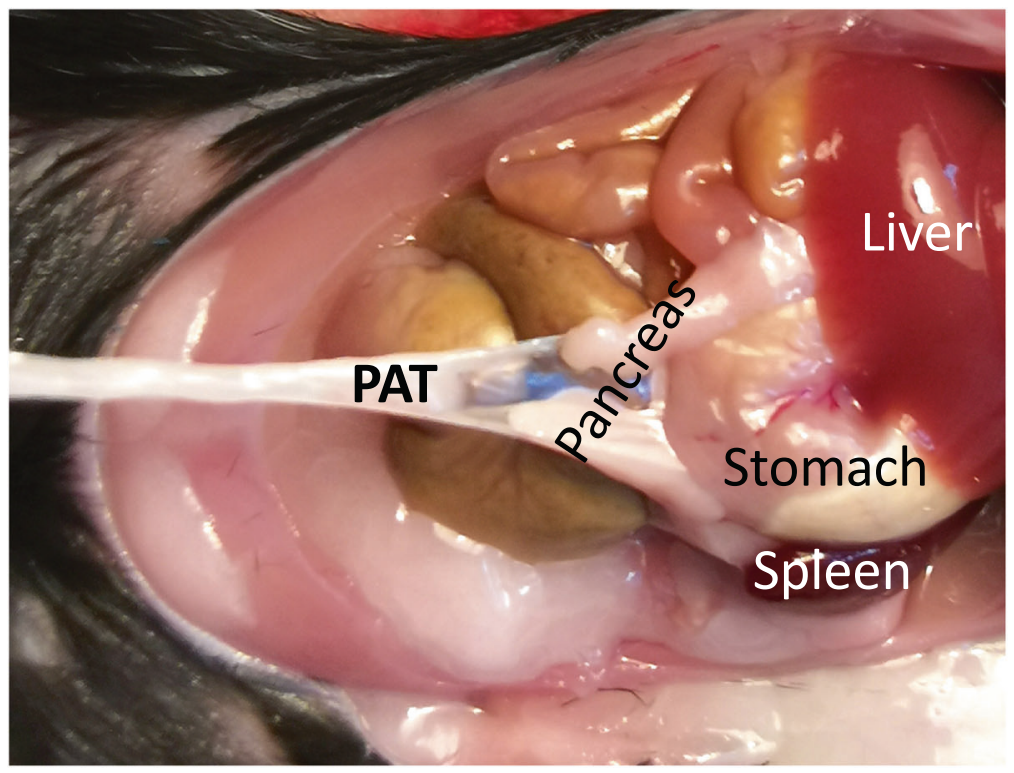

B)

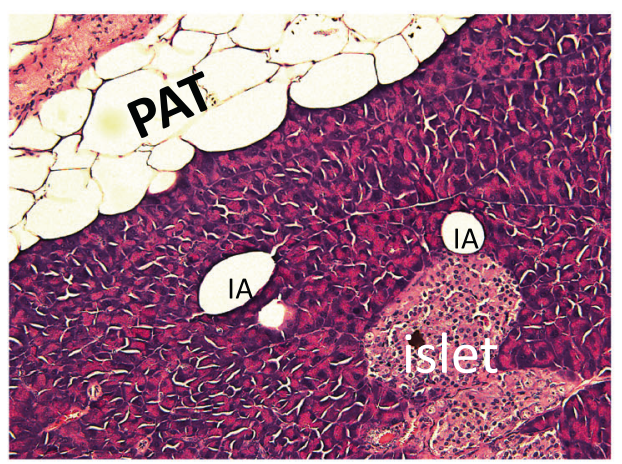

D)

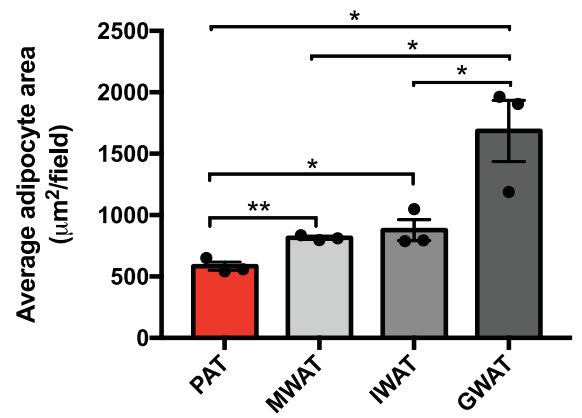

Fig. 1 Anatomical and morphological characterization of PAT in chow-diet-fed male mice. a Anatomical location of mouse PAT. Representative b H\&E and c perilipin-1 (red) stained sections of mouse pancreas including PAT versus intrapancreatic adipocytes (IA). Adipocyte size of PAT, MWAT, IWAT and GWAT in d chow-diet-
C)

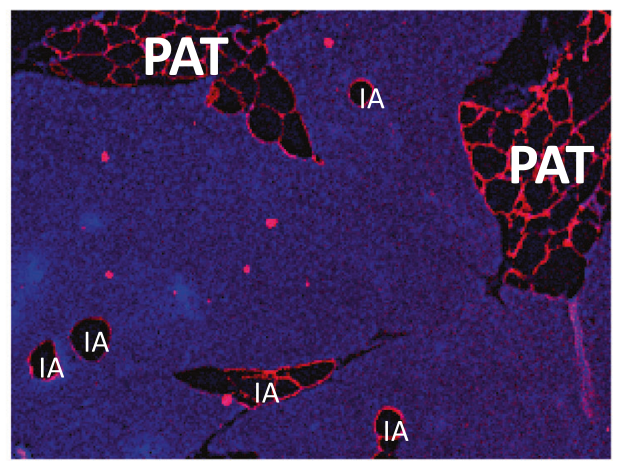

E)

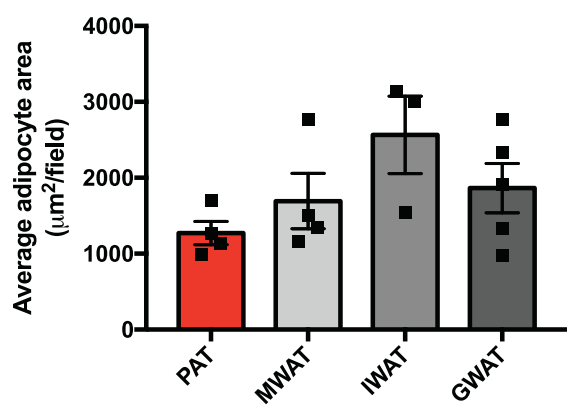

fed mice ( $n=7-10$ mice) and e 8-week HFD-fed mice ( $n=4-5$ mice). All values are expressed as mean \pm SEM. $* p<0.05$ and $* * p<0.01$ for the indicated comparisons. PAT peripancreatic adipose tissue, MWAT mesenteric adipose tissue, IWAT inguinal adipose tissue, and GWAT gonadal adipose tissue. 
mice, whereas subcutaneous fat transplantation had no effect [8].

One possible explanation for the association between visceral adiposity and increased disease risk is that visceral adipose tissue is more prone to become chronically inflamed than subcutaneous adipose tissue [3, 4, 9]. However, there are also regional differences with respect to lipolysis [10], fatty acid storage [11], adipokine secretion [6], and overall gene expression profile $[12,13]$. Thus, there are intrinsic metabolic and immunological differences between visceral and subcutaneous adipose tissue.

Peripancreatic adipose tissue (PAT) is a visceral fat depot that should not be confused with intrapancreatic adipocytes, which have received significant attention the past 15 years (as reviewed in ref. [14]). Both PAT and intrapancreatic adipocytes are implicated in the development of diabetes, but whether peripancreatic and intrapancreatic adipocytes display similar function and/or stem from similar precursor cells are currently unknown. Intrapancreatic adipocytes appear to arise within pancreas primarily when conditions are sufficiently adipogenic such as in response to high-fat diet (HFD) feeding in mice [1517]. The amount of intrapancreatic adipocytes correlates with the pancreatic fat content and have been suggested to protect the pancreas against ectopic lipid deposition, but these adipocytes could also affect islet functionality positively or negatively through their release of adipokines and fatty acids [15-18]. In contrast, PAT is a distinct fat depot containing both adipocytes and "non-adipocytes". To date, only a few studies have focused on PAT, but evidence for cross talk between PAT and beta cells during the development of obesity has been provided from a combination of transcriptomics, proteomics, and metabolomics of PAT and islets in rats [19]. It has also been shown that obesityand diabetes-induced changes in PAT, but not gonadal (GWAT) and inguinal white adipose tissues (IWAT), secretome increase beta-cell proliferation in vitro [20, 21]. Moreover, mouse and human PAT depots have also been shown to contain inflammatory foci in the form of lymphoid-like structures [22, 23], and pro-inflammatory activity of PAT has been suggested to be responsible for the HFD/obesity-induced acceleration of pancreatic neoplasia in a mouse model of pancreatic cancer [23]. Nevertheless, the intrinsic characteristics of PAT and its potential role in diabetes are still largely unknown. Here, we have performed a morphological and functional study of PAT in comparison with the more commonly studied mesenteric (M)WAT, GWAT, and IWAT in mice. We demonstrate that PAT constitutes a metabolically active fat depot that contains small adipocytes and a relatively large amount of stromal vascular cells. Furthermore, surgical removal of PAT aggravated hepatic steatosis and hyperinsulinemia in HFD-induced obesity.

\section{Material and methods}

\section{Animals and design of diet-induced obesity study}

All animal experiments were approved by the Animal Ethics Committee at the Administrative Court of Appeals in Gothenburg, Sweden. Adult male C57Bl/6J wild-type mice (Charles River, Sulzfeld, Germany) were maintained with ad libitum access to water and standard chow diet as previously described [24]. In the diet-induced obesity time course study, mice were randomly assigned to groups and fed standard chow or HFD (60\% fat, $20 \%$ protein, and $20 \%$ carbohydrate, D12492, Research Diets Inc., New Brunswick, NJ, USA) the last $1,4,8$, and 16 weeks before tissue collection at 16 weeks of age (except the 16-week chow and HFD groups, which were sacrificed at 24 weeks of age). All animals were fasted for $4 \mathrm{~h}$ prior tissue collection. Trunk blood (serum) was collected, GWAT (unilaterally), IWAT (unilaterally), MWAT, PAT, pancreas, and liver were weighed and either snap-frozen in liquid nitrogen and stored at $-80^{\circ} \mathrm{C}$ until analysis or collected for histological analysis. Lipid and glucose uptake studies, flow cytometry, quantiative real-time PCR, perilipin-1 staining, and histological methods are described in Supplementary methods.

\section{Surgical removal of PAT}

Littermate male $C 57 B / / 6 J$ mice (8-10 weeks of age) were randomly divided into control or PAT-ectomy groups, anaesthetized with isoflurane (Apoteksbolaget, Göteborg, Sweden, $2.0 \%$ air mixture) and placed on a heated pad to reduce heat loss. The mice were incised in their left side of abdomen and PAT $(5 \pm 0.4 \mathrm{mg})$ was identified in the peritoneal cavity using spleen as a landmark (Fig. 1a). PAT was carefully resected in the PAT-ectomy group while control mice underwent sham surgery where PAT was cut but not removed. Therafter the peritoneum was sutured (V489H, resorbable polyglactin 910, Coated VICRYL Ethicon Inc, Scotland), the skin stapled (Reflex 7-mm clip system, Agntho's, Sweden), and to relieve postoperative pain Temgesic $(0.05 \mathrm{mg} / \mathrm{kg}$; Apoteksbolaget) was given intraperitoneally. Prior to being returned to home cages, the mice were allowed to recover on a heated pad. Oral glucose tolerance test, tissue triglyceride quantification, islet and PAT co-culture, and glucose-stimulated insulin secretion are described in Supplementary methods.

\section{Statistical analyses}

GraphPad Prism 7 (GraphPad Software, San Diego, CA, USA) was used for statistical analysis. The sample sizes in each experiment are provided in results text and in figure legends. Only ill and/or wounded animals were excluded 
A)
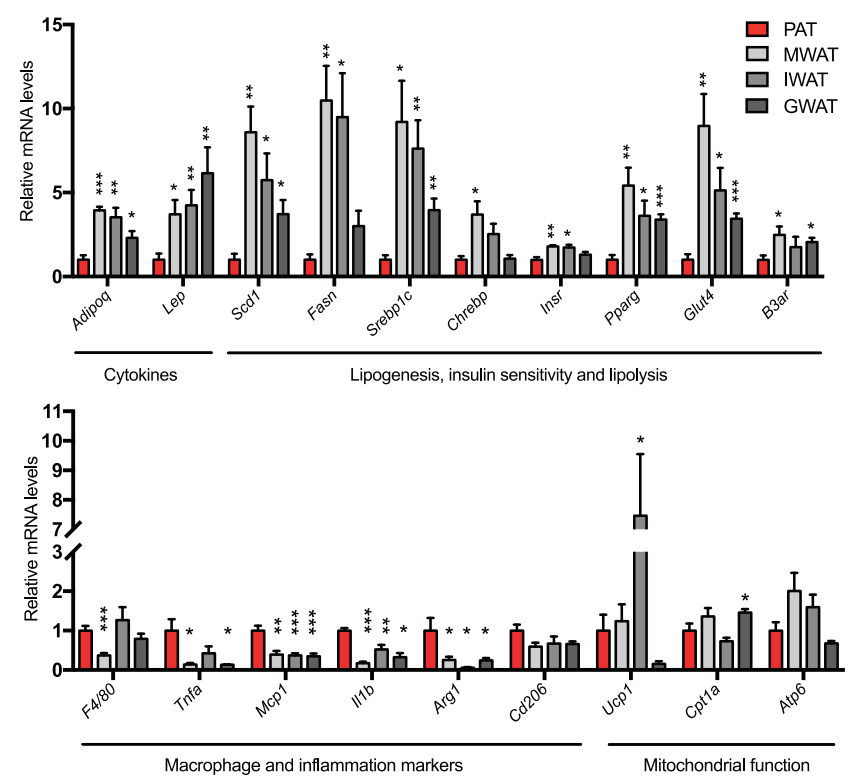

B)

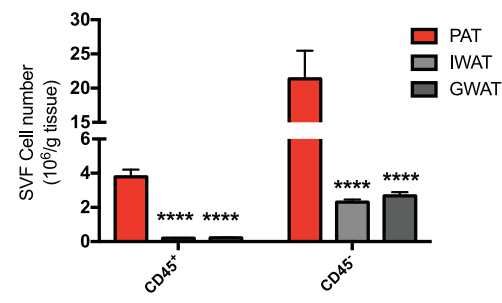

D)
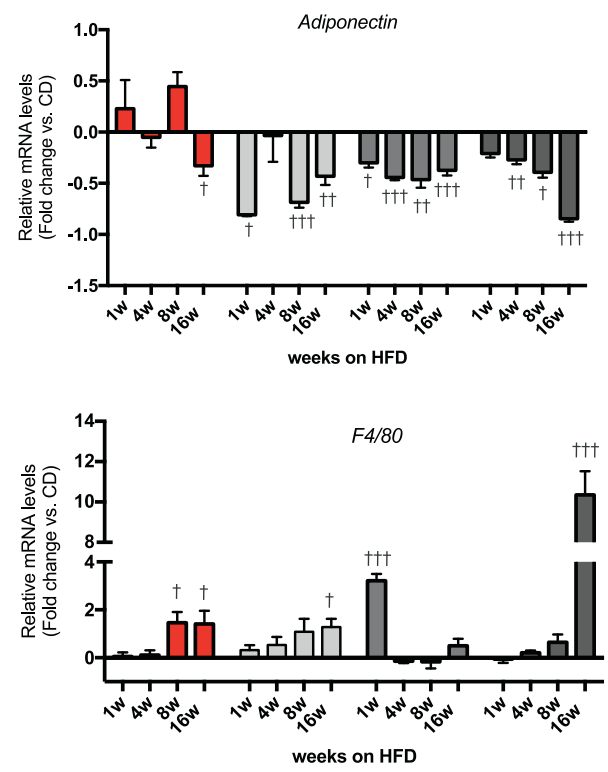

from the analyses ( $n=3$ in this study). Data are presented as mean \pm SEM. Comparisons were performed using oneway or two-way ANOVA or two-tailed Student's $t$ test. The
C)

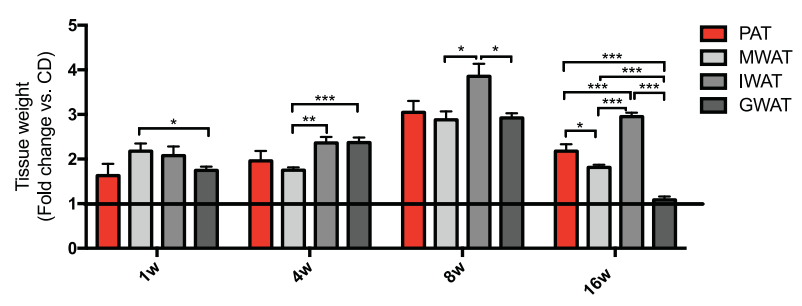

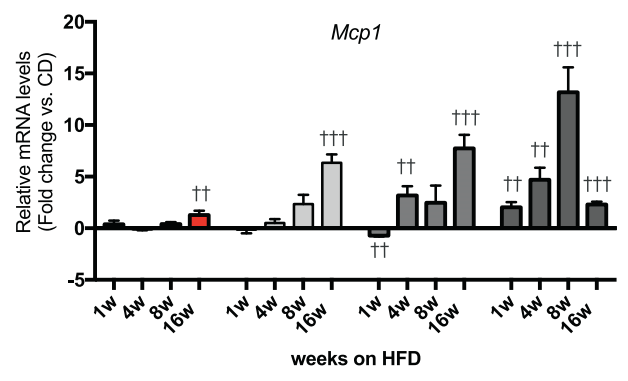

variance was similar between compared groups. Pearson $r$ correlation was used to measure the degree of the relationship between adipose tissue and liver weights. Data 
Fig. 2 Gene expression profile assessed by quantitative real-time PCR in PAT, MWAT, IWAT, and GWAT. a Relative mRNA levels in PAT, MWAT, IWAT, and GWAT on chow-diet conditions (normalized to Actb). Data are expressed relative to the level in PAT. b FACS analysis of $\mathrm{CD}^{4} 5^{+}$(leukocytes) and $\mathrm{CD}^{-} 5^{-}$cells in SVF isolated from PAT, IWAT, and GWAT. c Tissue weights of PAT, MWAT, IWAT, and GWAT in mice after 1-, 4-, 8- and 16-week HFD feeding, represented as fold-change from chow-diet-fed aged matched controls. d Relative mRNA levels in PAT, MWAT, IWAT, and GWAT in mice after 1-, 4-, 8- and 16-week HFD feeding (normalized to Actb and Tbp), represented as fold-change from chow diet. All values are expressed as mean $\pm \operatorname{SEM}(n=6$ mice/group in 1,4 , and 8 weeks on HFD vs. CD; $n=10$ mice/group in 16 weeks on HFD vs. CD). $* p<0.05, * * p<0.01$, and $* * * p<0.001$ for PAT vs. other depots; $\uparrow p<0.05, \dagger \dagger p<0.01$, and $\dagger \dagger \uparrow p<0.001$ for mice-fed high-fat diet vs. chow diet. Adipoq adiponectin, Lep leptin, Scdl stearoylcoenzyme A desaturase 1, Fasn fatty acid synthase, Srebplc sterol regulatory element-binding transcription factor-1c, Chrebp carbohydrate-responsive element-binding protein, Ins $r$ insulin receptor, Pparg peroxisome proliferator-activated receptor gamma, Glut4 glucose transporter type 4, B3ar adrenoceptor beta 3, Tnfa tumor necrosis factor alpha, Mcp 1 monocyte chemoattractant protein-1, $I l 1 b$ interleukin-1 beta, Arg1 arginase 1, Cd206 macrophage mannose receptor C-type 1, Ucp1 uncoupling protein-1, Cpt1b carnitine palmitoyltransferase 1b, Atp6 ATP synthase 6, PAT peripancreatic adipose tissue, MWAT mesenteric adipose tissue, IWAT inguinal adipose tissue, and GWAT gonadal adipose tissue.

were log-transformed as necessary to achieve normal distributions and $p<0.05$ was considered significant.

\section{Results}

\section{PAT contains smaller adipocytes than MWAT, IWAT, and GWAT}

PAT is an independent fat depot, distinct from intrapancreatic adipocytes, that is located in the ventromedial area attached to the pancreas (Fig. 1a-c). In healthy chow-fed mice PAT weighed $5-10 \mathrm{mg}, \sim 0.2 \%$ of the total fat mass based on DEXA data [25]. We found that PAT adipocytes were on average smaller than MWAT, IWAT, and GWAT adipocytes (Fig. 1d). Also, the maximal adipocyte size was smaller in PAT than in the other fat pads (Supplementary Fig. 1A). These differences disappeared following 8-week HFD feeding (Fig. 1e and Supplementary Fig. 1B).

\section{PAT displays an altered cellular composition compared to other fat depots}

PAT displayed a different gene expression profile compared to MWAT, IWAT, and GWAT. The mRNA levels of genes encoding leptin, adiponectin, markers of lipogenesis, insulin sensitivity, and lipolysis were significantly lower in PAT than in MWAT, IWAT, and GWAT. Conversely, the expression of many inflammatory markers was higher in PAT. PAT also displayed higher expression of the M2-type macrophage marker arginase 1 and a similar trend was seen for the macrophage mannose receptor Ctype $1(\mathrm{Cd} 206)$. Atp6 and other mitochondrial markers levels were similar between depots except for a higher expression of Ucpl and Cptla in IWAT and GWAT, respectively (Fig. 2a). Despite this gene expression pattern, PAT adipocytes appeared just as functional as MWAT adipocytes judged by basal and insulin-stimulated de novo lipogenesis (Supplementary Fig. 1C). Lipolysis, induced by $\beta_{3}$-adrenergic receptor agonist CL-316,243 (CL), was greater in PAT adipocyte while there was a trend toward decreased basal lipolysis in PAT compared to MWAT adipocytes (Supplementary Fig. 1D). Based on these data, we hypothesized that the altered gene expression pattern reflects a different cellular composition (with fewer adipocytes and more leukocytes in PAT) rather than an elevated pro-inflammatory dysfunctional state. Indeed, PAT displayed ten times more stromal vascular cells per $\mathrm{g}$ of tissue compared to IWAT or GWAT (Fig. 2b). Furthermore, PAT contained more fibroblasts, more macrophages, more dendritic cells, and more lymphocytes than IWAT and GWAT (Supplementary Fig. 1E).

\section{PAT is protected against some of the HFD-induced transcriptional changes in adipose tissue}

Body weight in HFD-fed mice increased by $13 \%, 22 \%$, $52 \%$, and $54 \%$ after $1,4,8$, and 16 weeks, respectively, compared to age-matched chow-fed control mice (Supplementary Fig. 2A, B). The relative fat pad weight increase compared to chow controls was similar between PAT and the other fat depots for the first 8 weeks on HFD (Fig. 2c). After 16-week HFD feeding, PAT showed a higher relative weight increase compare to MWAT $(p=0.03)$ and GWAT $(p<0.001)$, although IWAT gained most weight of the four fat depots $(p<0.001)$ (Fig. 2c). The relative difference in fat depot weight between HFD- and chow-fed mice at 16 weeks was reduced compared to the 8-week HFD group. The reason for this relative reduction is due to significant fat mass gain also in the ad libitum chow-fed controls (Supplementary Table 1). Despite similar relative fat depot weight gain during the first 8 weeks on HFD, the gene expression pattern was different in PAT compared to the other fat depots. In PAT, the adiponectin mRNA levels were reduced only after 16 weeks on HFD, while the expression of these genes was reduced already after 1-week HFD feeding in the other fat depots (Fig. 2d). The proinflammatory cytokine Tnfa increased slightly after 1-week HFD feeding in PAT and IWAT, while GWAT displayed a marked increase after 16 weeks on HFD (Fig. 2d). The PAT and MWAT mRNA levels of the pan-macrophage marker F4/80 increased with duration of HFD. For IWAT and 


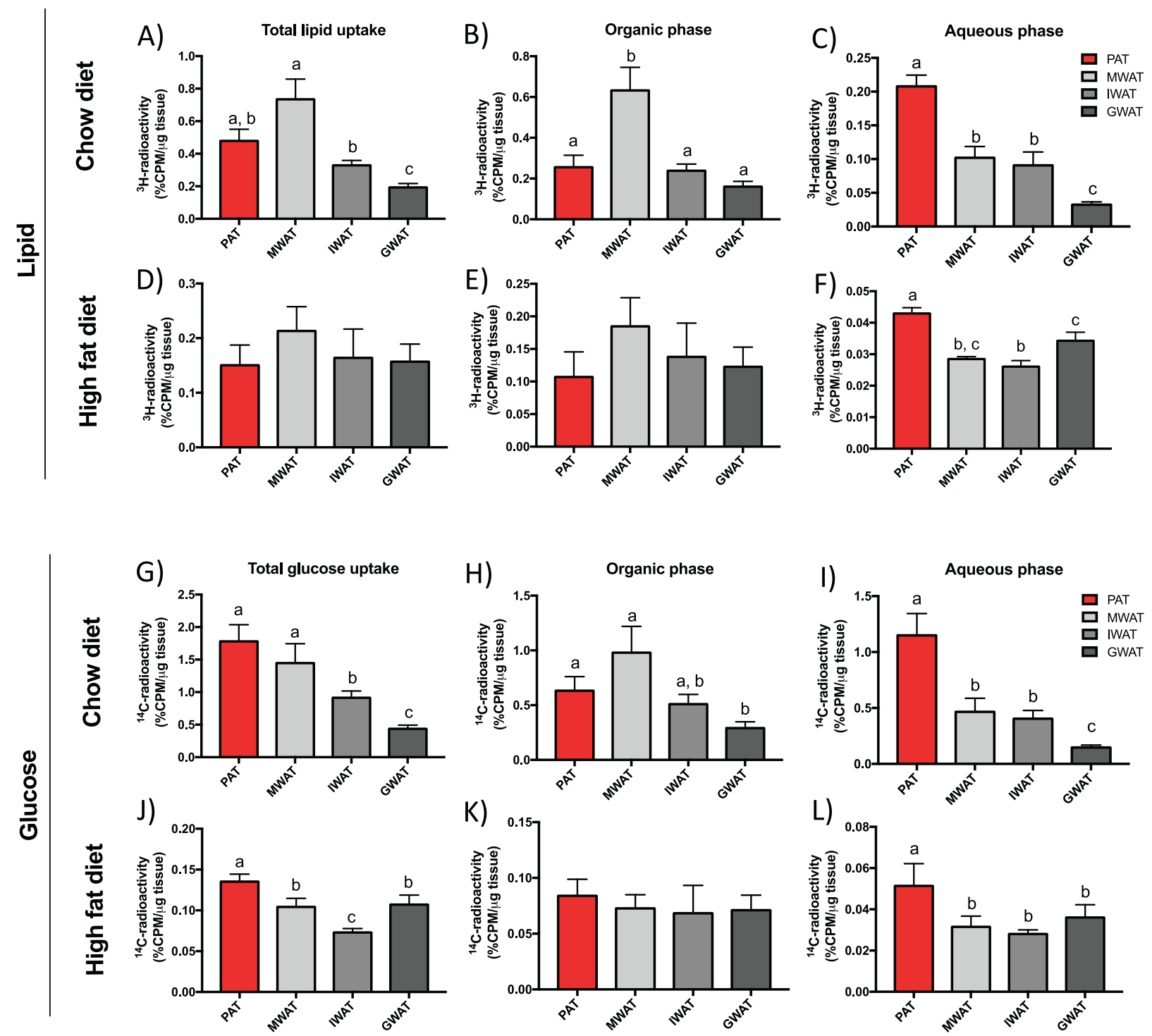

Fig. 3 Lipid and glucose metabolism in PAT, MWAT, IWAT, and GWAT in chow- and 16-week HFD-fed male mice. a, d Total lipid uptake, b, e triglyceride accumulation (organic phase), and $\mathbf{c}, \mathbf{f}$ lipid oxidation (aqueous phase) in different fat depots in respectively, chow ( $n=8-11$ mice/group) and 16-week HFD-fed mice $(n=5-6$ mice/ group). $\mathbf{g}, \mathbf{j}$ Total glucose uptake, $\mathbf{h}, \mathbf{k}$ de novo lipogenesis from

GWAT, the F4/80 responses were more variable: large increases were observed after 1 week (IWAT) and 16 weeks (GWAT), but not at other times (Fig. 2d). The monocyte chemoattractant Mcpl was modestly regulated in PAT with a significant increase only after 16 weeks on HFD. A similar pattern was seen in MWAT although the HFD-induced upregulation at 16 weeks was higher than in PAT. In contrast, GWAT Mcpl levels were upregulated throughout the HFD-time course and highest after 8-week HFD feeding, and IWAT Mcpl levels were reduced after 1 week on HFD followed by an upregulation after 4 and 16 weeks on HFD (Fig. 2d). glucose (organic phase), and $\mathbf{i}, \mathbf{l}$ glucose catabolism (aqueous phase) in respectively, chow ( $n=8$ mice/group) and 16-week HFD-fed mice ( $n$ $=5-6$ mice/group). All values are expressed as mean \pm SEM. Values that do not share a common letter ( $\mathrm{a}, \mathrm{b}$, and $\mathrm{c})$ are statistically different. PAT peripancreatic adipose tissue, MWAT mesenteric adipose tissue, IWAT inguinal adipose tissue, and GWAT gonadal adipose tissue.

\section{PAT has a higher capacity for lipid oxidation and glucose uptake than MWAT, IWAT, and GWAT}

In chow-fed mice, total lipid uptake $\left({ }^{3} \mathrm{H}\right.$-triolein counts per $\mu \mathrm{g}$ tissue) varied between the different depots: highest in MWAT and lowest in GWAT with PAT being intermediate (Fig. 3a). Triglyceride accumulation (judged by the ${ }^{3} \mathrm{H}$ counts in the organic phase) was greatest in MWAT and 2 .5-fold higher than in the other depots (Fig. 3b). Interestingly, the depot with the highest lipid oxidation (judged by ${ }^{3} \mathrm{H}$ counts in the aqueous phase) was PAT where $43 \%$ of the total uptake was found in the aqueous phase compared to the $14 \%, 27 \%$, and $16 \%$ in 
Fig. 4 Pearson correlations between different fat depots and liver weight in chow and 16-week HFD-fed male mice. Pearson correlation was used to measure the degree of correlation between liver weight and, respectively, a PAT weight, b IWAT weight, $\mathbf{c}$ MWAT weight, and d GWAT weight. Black squares indicate mice fed with chow diet and white circles indicate mice fed with HFD. A $p$ value $<0.05$ indicates that the Pearson's correlations coefficient $(R)$ is significantly different from zero. PAT peripancreatic adipose tissue, MWAT mesenteric adipose tissue, IWAT inguinal adipose tissue, and GWAT gonadal adipose tissue.
A)

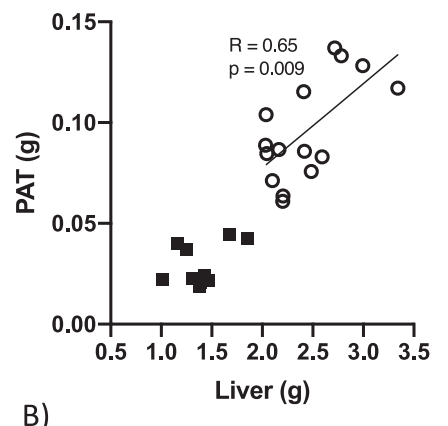

B)
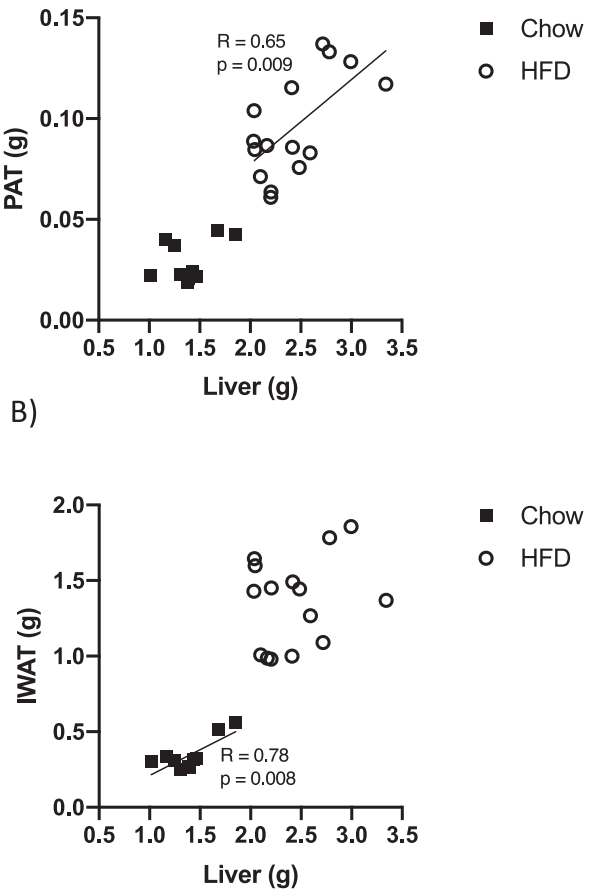

- Chow

- HFD
C)

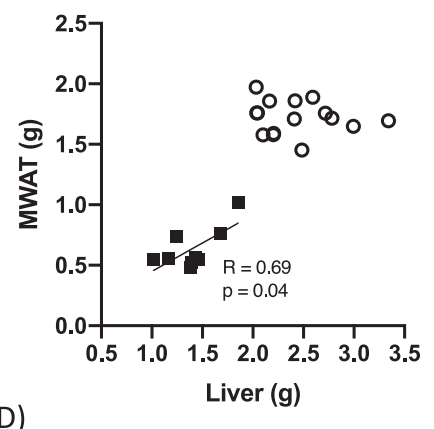

- Chow

- HFD

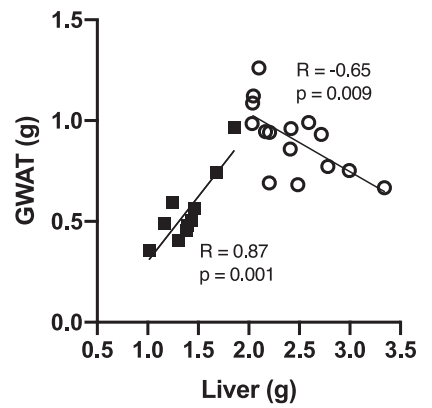

- Chow

- HFD
MWAT, IWAT, and GWAT, respectively (Fig. 3c). In micefed HFD for 16 weeks, the total lipid uptake and triglyceride accumulation were similar between depots (Fig. 3d, e). However, lipid oxidation was again highest in PAT (Fig. 3f).

In chow-fed mice, total glucose uptake in PAT and MWAT was similar, and higher than in IWAT and GWAT (Fig. 3g). In obese, HFD-fed conditions, PAT showed the highest glucose uptake: $30 \%, 85 \%$, and $26 \%$ greater than MWAT, IWAT, and GWAT, respectively (Fig. 3j). Lipogenesis (estimated from ${ }^{14} \mathrm{C}$ counts in the organic phase) was highest in MWAT and lowest in GWAT in chow-fed mice (Fig. 3h), whereas levels were similar between all fat depots in HFD-fed mice (Fig. 3k). For the aqueous phase (at least in part reflecting glucose oxidation), the highest ${ }^{14} \mathrm{C}$ counts were found in PAT where levels were tenfold higher than in GWAT in mice on chow (Fig. 3i). In HFD-fed mice, the highest ${ }^{14} \mathrm{C}$ counts in the aqueous phase were also found in PAT with levels in the other depots being about half (Fig. 31). Collectively, these data suggest that PAT is a metabolically active depot with a relatively high capacity for lipid and glucose oxidation.

\section{PAT weight is positively correlated with liver weight in HFD-induced obesity}

We performed correlation analyses of body, adipose tissue, and liver weights. In lean chow-fed mice, there was a positive correlation between body weight and the weight of all fat depots. There was also a positive correlation between body and liver weights (Supplementary Table 2). Following 16 weeks on HFD, there was a positive correlation between IWAT and liver weight and a similar trend was seen for PAT (Supplementary Table 2). In contrast, there was no correlation between body weight and GWAT and body weight and MWAT, possibly indicating that these depots have reached their maximal size and cannot expand further (Supplementary Table 2). It has been reported that there is a significant amount of adipocyte death in GWAT after chronic HFD feeding [26], which may explain the paradoxical relative reduction in GWAT size in advanced obesity in mice. In chow-fed mice, there was a positive correlation between liver weight and the weight of MWAT, IWAT, and GWAT (Fig. 4b-d; black symbols; $p=0.04, p=0.008, p=0.001$, respectively). A similar trend, albeit not statistically significant, was observed for PAT (Fig. 4a). In HFD-fed mice, only PAT weight showed a clear significant correlation with liver weight (Fig. 4a; white circles; $p=0.009$ ). For the other depots, no such correlation was observed and for GWAT a negative correlation was observed (Fig. 4b-d).

\section{Surgical removal of PAT aggravates HFD-induced hepatic steatosis}

Healthy adipose tissue expansion protects against ectopic lipid deposition in the liver [1]. Consequently, hepatic steatosis suggests that excess calories are not efficiently stored in adipose tissue, possibly reflecting adipocyte insulin resistance and inability to expand the fat depots. 
A)

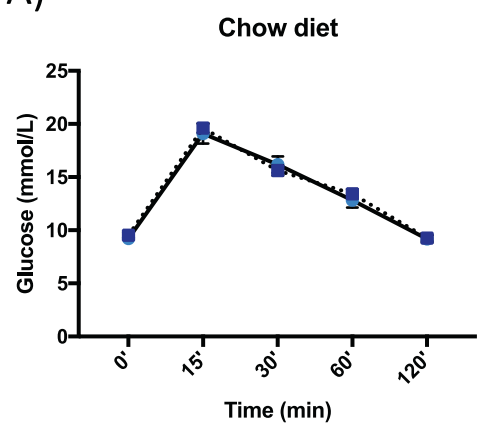

B)

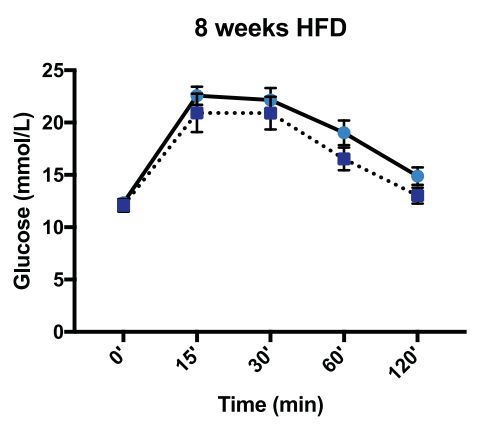

C)

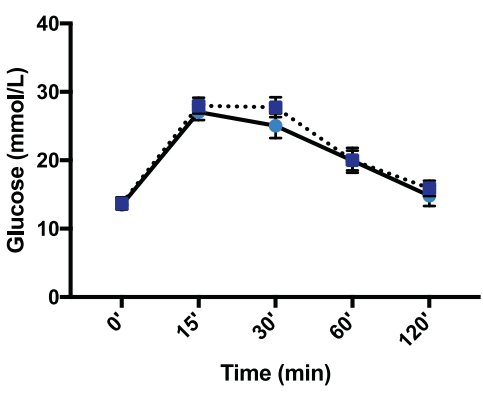

D)

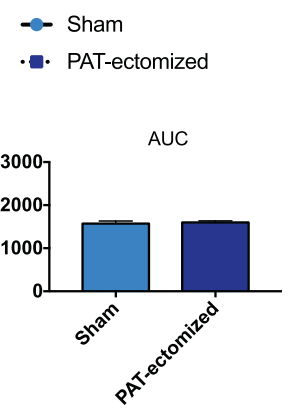

E)

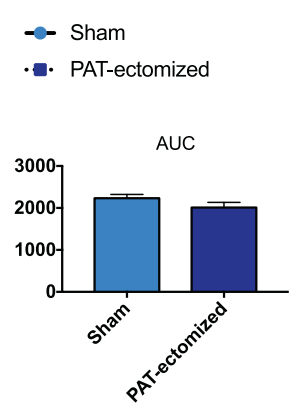

F)

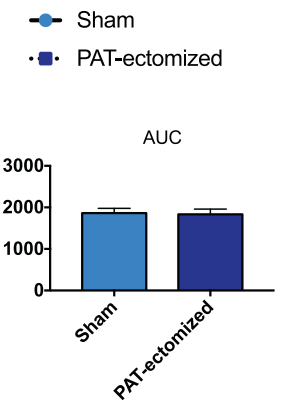

Fig. 5 Oral glucose tolerance tests in male PAT-ectomized and sham control mice on chow diet and after 8- and 16-week HFDfeeding. Circulating glucose levels at indicated time points and AUC in response to oral glucose load in PAT-ectomized and sham controls mice on a chow diet (CD; $n=7-9$ mice/group), after $\mathbf{b} 8$ weeks on

Thus, we reasoned that the observed positive correlation between PAT and liver weight in advanced obesity (that was not seen for the other three fat depots) suggests that PAT can continue to store excess calories when IWAT, MWAT, and GWAT have reached their limit for healthy expansion. To test this we studied the impact of PAT removal on metabolic function and hepatic steatosis (Supplementary Fig. 3A). Control mice underwent sham surgery. The mice tolerated the surgery well and there was no difference in HFD-induced body-weight gain between the groups. PAT weight in PAT-ectomized mice was only $18 \%$ of that in controls after 16-week HFD feeding $(103 \pm 11 \mathrm{mg}$ vs. $19 \pm 5 \mathrm{mg}, p<0.001)$. Thus, our surgical procedure led
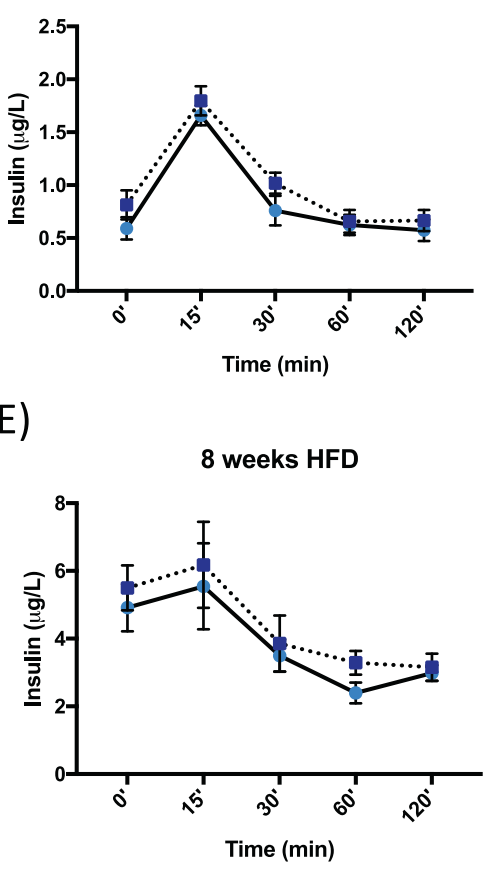

- Sham

- PAT-ectomized
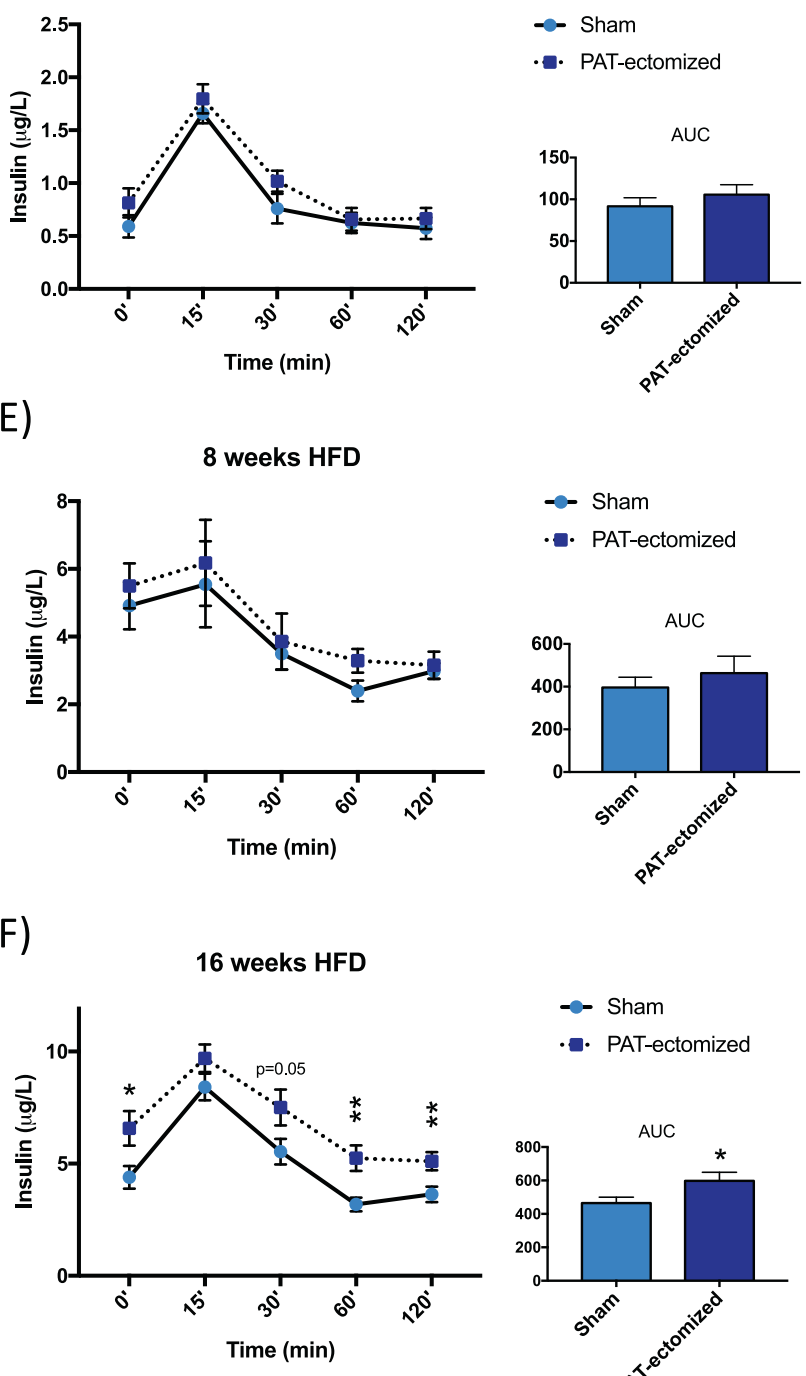

- Sham

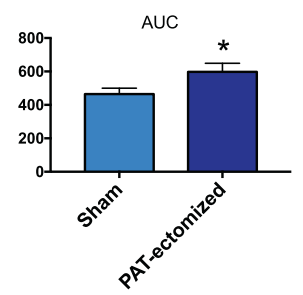

$\operatorname{HFD}(n=8-10$ mice/group), and c 16 weeks on HFD ( $n=8-10$ mice/ group). Circulating insulin levels at indicated time points and AUC in response to oral glucose load in PAT-ectomized and sham controls mice on $\mathbf{d}$ chow diet, after $\mathbf{e} 8$ weeks on HFD, and $\mathbf{f} 16$ weeks on HFD. All values are expressed as mean \pm SEM. $* p<0.05$.

to a significant difference in the resultant PAT size in HFDchallenged mice although PAT to some extent regenerated over time. The average PAT adipocyte size was similar between groups $\left(6547 \pm 853 \mu \mathrm{m}^{2}\right.$ in controls vs. $6299 \pm$ $430 \mu^{2}$ in PAT-ectomized mice, $n=4+5, p=0.79$ ). However, there was a difference in size distribution with fewer adipocytes of the smallest size and more adipocytes of the medium to large size in the regenerated PAT of PATectomized mice (Supplementary Fig. 3B). No compensatory increase of IWAT, MWAT, or GWAT weight was detected in PAT-ectomized mice (Supplementary Fig. 3C).

Oral glucose tolerance tests performed on mice fed chow and after 8-week HFD feeding revealed no differences
-. PAT-ectomized 
A)

D)
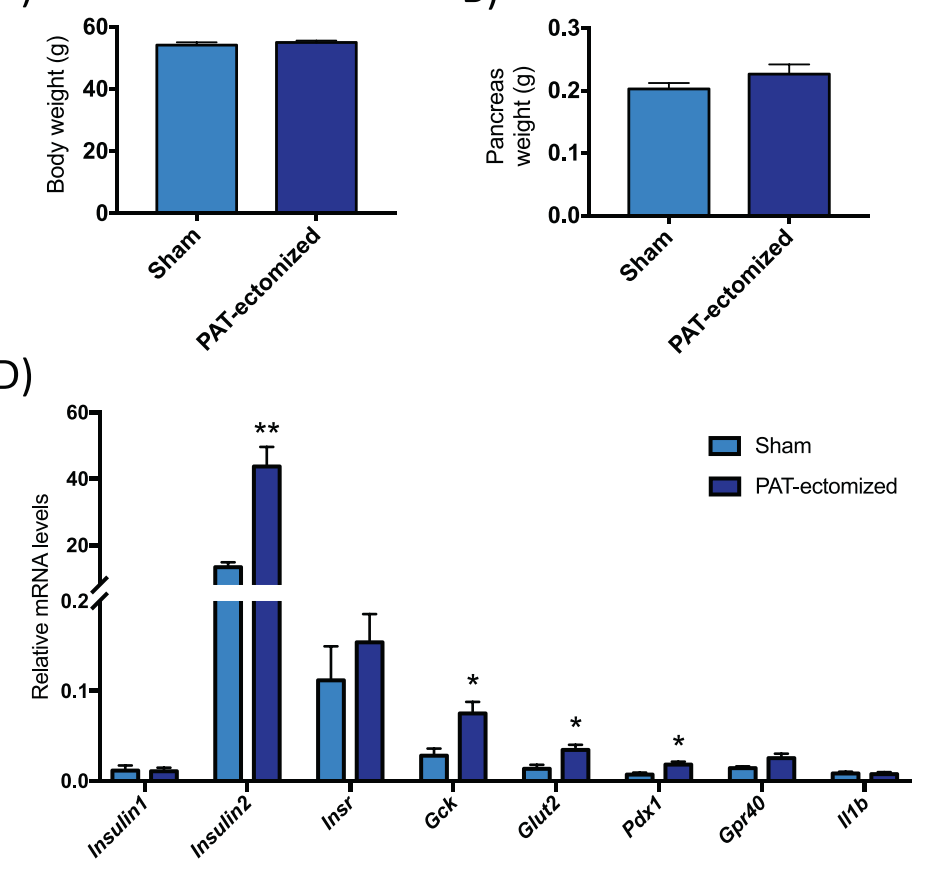

B)

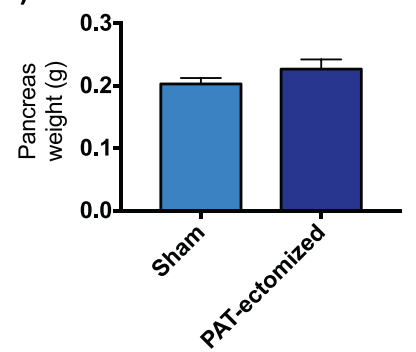

C)

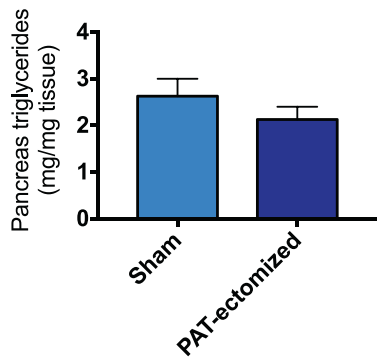

E)

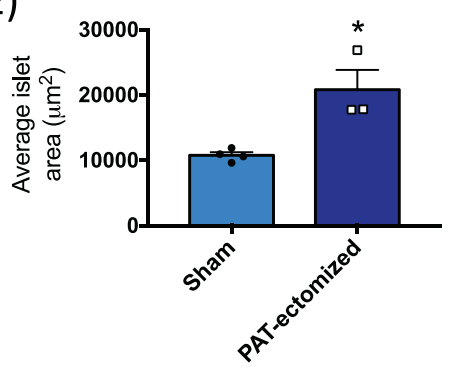

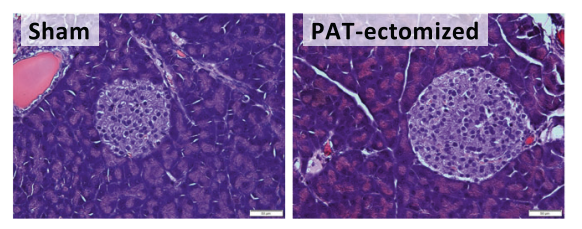

F)

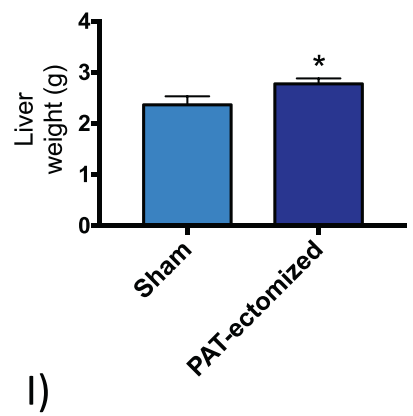

G)

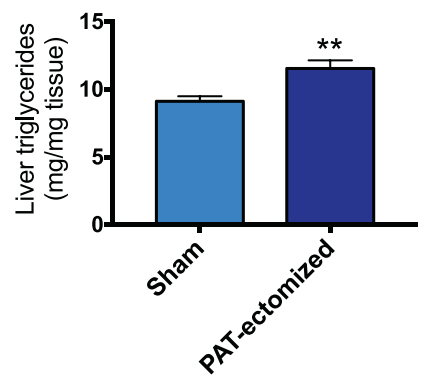

H)
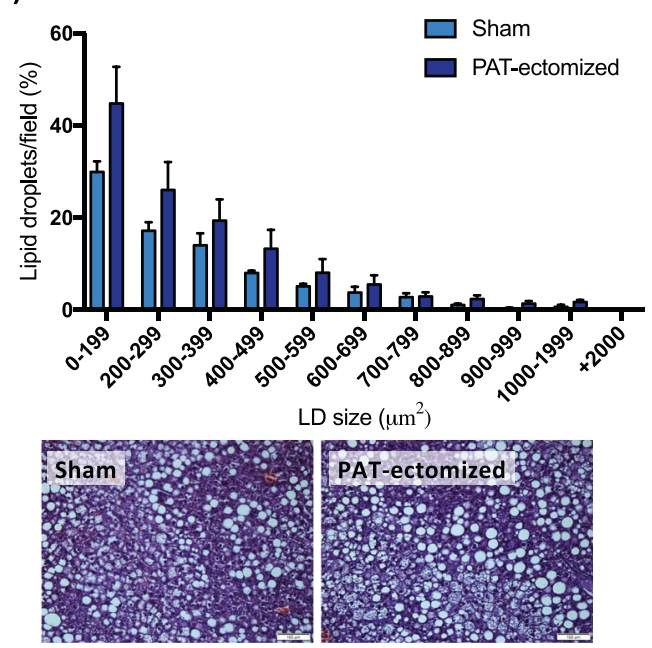

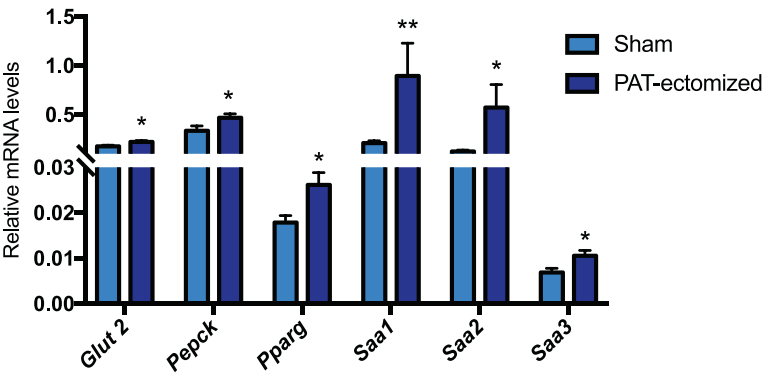

Fig. 6 Effect of PAT-ectomy on body weight and, hepatic and pancreatic ectopic lipid deposition and gene expression after 16week HFD feeding in male mice. a Body weight, b pancreas weight, c pancreatic triglyceride content, and $\mathbf{d}$ pancreatic gene expression in PAT-ectomized and sham control mice ( $n=8-10$ mice/group). e Average pancreatic islet area in PAT-ectomized and sham control mice and representative H\&E sections ( $n=3-4$ mice/group). f Liver weight, $\mathbf{g}$ hepatic triglyceride content, $\mathbf{h}$ hepatic lipid droplet distribution and representative H\&E section ( $n=4-6$ mice/group), and $\mathbf{i}$ hepatic gene expression in PAT-ectomized and sham control mice $(n=8-10$ mice/ group). All values are expressed as mean \pm SEM. $* p<0.05$ and $* * p<$ 0.01 . 
between control and PAT-ectomized mice (Fig. 5a, b, d, e). As expected, serum insulin levels were greater than fivefold higher in HFD- than chow-fed mice (reflecting increased insulin resistance). After 16 weeks on HFD, PAT-ectomized mice displayed increased insulin levels (basal as well as after a glucose challenge) despite blood glucose and glucagon levels not being affected (Fig. 5c, f and glucagon levels of $10.0 \pm 2.3$ in controls $(n=7)$ and $7.2 \pm 1.3 \mathrm{pg} / \mathrm{mL}$ in PAT-ectomized mice $(n=10), p=0.27)$.

Body weight (Fig. 6a), pancreas weight (Fig. 6b) and its triglyceride content (Fig. 6c) did not significantly differ between control and PAT-ectomized mice. There were however weak trends toward reduced pancreatic triglyceride content (Fig. 6c, $p=0.29$ ) and reduced number of intrapancreatic adipocytes $(p=0.17)$ in PAT-ectomized mice (23.6 \pm 4 adipocytes of an average size of $7649 \pm 625 \mu \mathrm{m}^{2}$ in controls vs. $14.8 \pm 4$ adipocytes of an average size of $7279 \pm 710 \mu \mathrm{m}^{2}$ in PAT-ectomized mice, $n=4+3$ ). Moreover, pancreatic mRNA levels of insulin (Ins2), glucokinase (Gck), glucose transporter 2 (Glut2, encoded by Slc2a2), and the pancreatic and duodenal homeobox $1(P d x l)$ were higher in PATectomized than in control mice (Fig. 6d). In accordance with this gene expression pattern, the average islet area was significantly larger in PAT-ectomized mice, while the number of islets per field were similar between groups (Fig. 6e and $24.9 \pm 4$ islets in controls vs. $26.5 \pm 5$ islets in PAT-ectomized mice, $n=4+3$ ). Furthermore, PAT-ectomized mice displayed more severe HFD-induced hepatic steatosis than controls; the liver weights were increased (Fig. 6f) along with increased triglyceride content (Fig. $6 \mathrm{~g}$ ). Thus, the total liver triglyceride content was almost $50 \%$ higher in PATectomized than in control mice. This increase in hepatic triglyceride levels was associated with larger lipid droplets and a trend toward increased "ballooning" i.e., enlarged cells with rarefied cytoplasm (Fig. 6h and Supplementary Fig. 3D). The hepatic expression of inflammatory markers serum amyloid a1, a2, and a3 (Saal-3), as well as markers of insulin resistance such as Glut2 (Slc2a2), phosphoenolpyruvate carboxylase (Pepck), and peroxisome proliferator-activated receptor gamma (Pparg), were elevated in PAT-ectomized mice compared to controls (Fig. 6i).

\section{PAT co-culture preserves islet functionality in vitro}

The close proximity of PAT to the pancreas suggests it may affect islet function. To test this, we analyzed the effect of PAT co-culture on insulin secretion in isolated islets. We found that 18-h co-culture with PAT at $11-\mathrm{mM}$ glucose slightly $(\sim 10 \%)$ reduced the insulin levels in the co-culture media (Supplementary Fig. 4A). In contrast, the insulin release in response to high glucose post co-culture was higher in the PAT co-culture group than in the controls. This difference in insulin release after co-culture was due to impaired glucose-stimulated insulin release in the control group (Supplementary Fig. 4B).

\section{Discussion}

Healthy adipose tissue can effectively store excess energy during nutrient overload. This storage capacity is often lost in obese individuals. However, the adverse consequences of obesity are not necessarily related to the total body-fat content, but rather to the fat distribution [6, 7]. In general, subcutaneous fat accumulation provokes less metabolic disturbances than visceral adiposity, which is strongly associated with insulin resistance and type- 2 diabetes [5, 7]. Nevertheless, subcutaneous fat expansion may also be pathological; insufficient adipogenic potential in the subcutaneous compartment may result in adipocyte hypertrophy and increased risk for developing type-2 diabetes [27, 28]. The PAT is a small fat depot closely located to MWAT within the visceral compartment, but differs from MWAT as well as from other fat depots, both structurally and functionally. We now show that PAT of unchallenged mice contains smaller adipocytes than the other fat depots, suggestive of a higher capacity for triglyceride storage and better sensitivity to insulin and adrenergic activation (cf. [1]). In keeping with this idea, lipolysis in PAT adipocytes displayed a greater sensitivity to CL than that observed in MWAT adipocytes, while insulin-stimulated lipogenesis was similar between the two depots. Interestingly, the lipid and glucose catabolism $\left(\left[{ }^{3} \mathrm{H}\right]-\right.$ triolein and $\left[{ }^{14} \mathrm{C}\right]$-glucose counts in the aqueous phase) was particularly high in PAT, indicating that it is a metabolically very active depot. The gene expression profile and the cellular composition in normal chow-diet mice was also different in PAT compared to the other fat depots. In essence, PAT displayed reduced expression of genes related to adipocyte function while the expression of macrophage and inflammatory markers was increased along with a higher number of leukocytes (including macrophages) per gram of tissue. Our gene expression and FACS data are also well in line with one human and one mouse study where PAT is identified as a highly heterogenous tissue with many different lymphoid-like structure and high immunological activity [22, 23]. In fact, one provocative idea is that the immune response on beta cells in type- 1 and type- 2 diabetes could be initiated by PAT [22]. Our mouse model will allow this hypothesis to be tested.

PAT also displayed relative resistance to the deleterious effects of HFD and the transcriptional changes were not as pronounced as in the other fat depots. For instance, we found decreased PAT adiponectin expression and increased PAT Mcpl expression only after 16 weeks on HFD. The PAT expression of the macrophage marker $F 4 / 80$ was however increased both at 8 and 16 weeks on HFD. A similar increase in $F 4 / 80$ without upregulated $M c p l$ was seen in IWAT after 
1-week HFD feeding. Mcpl is a chemokine that typically is involved in adipose tissue macrophage recruitment in obesity/ type-2 diabetes [29]. Thus, the increase in PAT and IWAT F4/80, respectively, at 8- and 1-week HFD feeding, may reflect another macrophage subtype than those seen in e.g., crown-like structures of adipose tissue in advanced obesity. For instance, an increased number of resident macrophages may be required for the necessary tissue remodeling to accommodate the growing adipocytes (or the adipocyte hyperplasia) during adipose tissue expansion [9, 30]. Moreover, the detected 1-week HFD-induced increase in Tnfa in IWAT and PAT is also in line with the idea that a potent acute inflammatory response is essential for healthy adipose tissue expansion [30]. These data suggest that PAT (similar to IWAT) has an intrinsically high capacity for healthy expansion, and start suffering from the deleterious effects of dietinduced obesity at later states than many other fat depots.

Visceral adiposity is highly associated with increased liver fat accumulation [31, 32] and is considered as a marker of dysfunctional subcutaneous adipose tissue. Visceral adiposity has been suggested to actively contribute to ectopic fat deposition and metabolic dysfunction through increased release of free fatty acids into the portal vein and increased production of pro-inflammatory cytokines [33, 34]. Moreover, lipectomy studies show that selective reduction in intraabdominal adipose tissue can improve the metabolic profile by reversing insulin resistance and glucose intolerance in human obesity [3]. Two clinical studies show that omental fat removal is associated with improved insulin sensitivity $[35,36]$, but such positive effect of visceral fat removal is not always observed $[37,38]$. The variable outcome from visceral fat removal may depend on the functionality of the excised adipose tissue. In order to elucidate whether PAT plays a significant role in obesity-associated metabolic disturbances, we surgically removed PAT in lean mice followed by a 16week long HFD-feeding regimen. Although PAT regenerated to some small extent, likely due to both hypertrophy of remnant adipocytes and formation of new adipocytes, there was still (after 16-week HFD feeding) a $>80 \%$ difference in PAT size between groups and we found that PAT-ectomized mice displayed higher basal and glucose-induced insulin levels associated with aggravated hepatic steatosis. Thus, PAT expansion protects against hepatic steatosis rather than being a contributing factor. The enhanced hyperinsulinemia in PATectomized mice did not stimulate increased intrapancreatic adipogenesis. If anything, there was a weak trend toward reduced amount of intrapancreatic adipocytes/fat in PATectomized mice possibly indicating that intrapancreatic adipocytes can arise from precursors that reside within PAT.

PAT has been suggested to play a direct role in the regulation of endocrine pancreas [19-21]. In some support of this idea, PAT co-culture preserved the insulin response to high glucose in isolated islets, implying that PAT can protect islets.
Thus, our co-culture data corroborate the report suggesting that PAT releases a factor that increases beta-cell viability/ functionality [20]. However, the islet-preserving effect of PAT could also stem from reduced glucotoxicity due to the competition for nutrients at co-culture conditions. In contrast, PAT removal increased beta-cell proliferation and the pancreatic Gck, Glut2, and $P d x l$ expression. We attribute these in vivo findings to compensatory beta-cell hyperplasia in response to HFD-induced systemic insulin resistance due to e.g., hepatic fat accumulation and inflammation [39].

In conclusion, additional studies are required to fully elucidate the role of PAT in the regulation of whole-body metabolism, pancreatic islets, and intrapancreatic adipogenesis. Nevertheless, our data suggest that PAT is a metabolically active fat depot with systemic metabolic effects far greater than suggested by its small size.

Acknowledgements We thank Dr Anders Ståhlberg for excellent assistance with the gene expression analysis. This research was funded by the Swedish Research Council (2012-1601, 2017-00792, and 20137107), the Novo Nordisk Foundation (NNF19OC0056601), Swedish Diabetes Foundation, the Royal Society of Arts and Sciences in Gothenburg, the IngaBritt and Arne Lundberg Foundation, and the Diabetes Research \& Wellness Foundation.

\section{Compliance with ethical standards}

Conflict of interest The authors declare that they have no conflict of interest.

Publisher's note Springer Nature remains neutral with regard to jurisdictional claims in published maps and institutional affiliations.

Open Access This article is licensed under a Creative Commons Attribution 4.0 International License, which permits use, sharing, adaptation, distribution and reproduction in any medium or format, as long as you give appropriate credit to the original author(s) and the source, provide a link to the Creative Commons license, and indicate if changes were made. The images or other third party material in this article are included in the article's Creative Commons license, unless indicated otherwise in a credit line to the material. If material is not included in the article's Creative Commons license and your intended use is not permitted by statutory regulation or exceeds the permitted use, you will need to obtain permission directly from the copyright holder. To view a copy of this license, visit http://creativecommons. org/licenses/by/4.0/.

\section{References}

1. Asterholm IW, Scherer PE. Enhanced metabolic flexibility associated with elevated adiponectin levels. Am J Pathol. 2010;176:1364-76.

2. Kusminski CM, Holland WL, Sun K, Park J, Spurgin SB, Lin Y, et al. MitoNEET-driven alterations in adipocyte mitochondrial activity reveal a crucial adaptive process that preserves insulin sensitivity in obesity. Nat Med. 2012;18:1539-49.

3. Foster MT, Pagliassotti MJ. Metabolic alterations following visceral fat removal and expansion: beyond anatomic location. Adipocyte. 2012;1:192-9. 
4. Kloting N, Fasshauer M, Dietrich A, Kovacs P, Schon MR, Kern $\mathrm{M}$, et al. Insulin-sensitive obesity. Am J Physiol Endocrinol Metab. 2010;299:E506-15.

5. Kwon H, Kim D, Kim JS. Body fat distribution and the risk of incident metabolic syndrome: a longitudinal cohort study. Sci Rep. 2017;7:10955.

6. Hill JH, Solt C, Foster MT. Obesity associated disease risk: the role of inherent differences and location of adipose depots. Horm Mol Biol Clin Investig. 2018;33:1868-91.

7. Neeland IJ, Turer AT, Ayers CR, Powell-Wiley TM, Vega GL, Farzaneh-Far R, et al. Dysfunctional adiposity and the risk of prediabetes and type 2 diabetes in obese adults. JAMA. 2012;308:1150-9.

8. Ohman MK, Shen Y, Obimba CI, Wright AP, Warnock M, Lawrence DA, et al. Visceral adipose tissue inflammation accelerates atherosclerosis in apolipoprotein E-deficient mice. Circulation. 2008;117:798-805.

9. Pellegrinelli V, Carobbio S, Vidal-Puig A. Adipose tissue plasticity: how fat depots respond differently to pathophysiological cues. Diabetologia. 2016;59:1075-88.

10. Fisher RM, Thorne A, Hamsten A, Arner P. Fatty acid binding protein expression in different human adipose tissue depots in relation to rates of lipolysis and insulin concentration in obese individuals. Mol Cell Biochem. 2002;239:95-100.

11. Hames KC, Koutsari C, Santosa S, Bush NC, Jensen MD. Adipose tissue fatty acid storage factors: effects of depot, sex and fat cell size. Int J Obes. 2015;39:884-7.

12. Gesta S, Tseng YH, Kahn CR. Developmental origin of fat: tracking obesity to its source. Cell. 2007;131:242-56.

13. Vidal H. Gene expression in visceral and subcutaneous adipose tissues. Ann Med. 2001;33:547-55.

14. Gerst F, Wagner R, Oquendo MB, Siegel-Axel D, Fritsche A, Heni M, et al. What role do fat cells play in pancreatic tissue? Mol Metab. 2019;25:1-10.

15. Pinnick KE, Collins SC, Londos C, Gauguier D, Clark A, Fielding BA. Pancreatic ectopic fat is characterized by adipocyte infiltration and altered lipid composition. Obesity. 2008;16:522-30.

16. Murakami R, Saisho Y, Watanabe Y, Inaishi J, Tsuchiya T, Kou $\mathrm{K}$, et al. Pancreas fat and beta cell mass in humans with and without diabetes: an analysis in the Japanese population. J Clin Endocrinol Metab. 2017;102:3251-60.

17. Gerst F, Wagner R, Kaiser G, Panse M, Heni M, Machann J, et al. Metabolic crosstalk between fatty pancreas and fatty liver: effects on local inflammation and insulin secretion. Diabetologia. 2017;60:2240-51.

18. Quiclet C, Dittberner N, Gassler A, Stadion M, Gerst F, Helms A, et al. Pancreatic adipocytes mediate hypersecretion of insulin in diabetes-susceptible mice. Metab Clin Exp. 2019;97:9-17.

19. Malpique R, Figueiredo H, Esteban Y, Rebuffat SA, Hanzu FA, Vinaixa $M$, et al. Integrative analysis reveals novel pathways mediating the interaction between adipose tissue and pancreatic islets in obesity in rats. Diabetologia. 2014;57:1219-31.

20. Palau N, Rebuffat SA, Altirriba J, Piquer S, Hanzu FA, Gomis R, et al. Role of IGFBP-3 in the regulation of beta-cell mass during obesity: adipose tissue/beta-cell cross talk. Endocrinology. 2012;153:177-87.

21. Rebuffat SA, Sidot E, Guzman C, Azay-Milhau J, Jover B, Lajoix $\mathrm{AD}$, et al. Adipose tissue derived-factors impaired pancreatic betacell function in diabetes. Biochim Biophys Acta Mol Basis Dis. 2018;1864:3378-87.

22. Ionescu-Tirgoviste C, Gagniuc PA, Gubceac E, Mardare L, Popescu I, Dima S, et al. A 3D map of the islet routes throughout the healthy human pancreas. Sci Rep. 2015;5:14634.
23. Hertzer KM, Xu M, Moro A, Dawson DW, Du L, Li G, et al. Robust early inflammation of the peripancreatic visceral adipose tissue during diet-induced obesity in the KrasG12D model of pancreatic cancer. Pancreas. 2016;45:458-65.

24. Benrick A, Chanclón B, Micallef P, Wu Y, Hadi L, Shelton JM, et al. Adiponectin protects against development of metabolic disturbances in a PCOS mouse model. Proc Natl Acad Sci. 2017;114:E7187-E96.

25. Benrick A, Wallenius V, Asterholm IW. Interleukin-6 mediates exercise-induced increase in insulin sensitivity in mice. Exp Physiol. 2012;97:1224-35.

26. Strissel KJ, Stancheva Z, Miyoshi H, Perfield JW, DeFuria J, Jick $\mathrm{Z}$, et al. Adipocyte death, adipose tissue remodeling, and obesity complications. Diabetes. 2007;56:2910-8.

27. Gustafson B, Hammarstedt A, Hedjazifar S, Smith U. Restricted adipogenesis in hypertrophic obesity: the role of WISP2, WNT, and BMP4. Diabetes. 2013;62:2997-3004.

28. Acosta JR, Douagi I, Andersson DP, Backdahl J, Ryden M, Arner $\mathrm{P}$, et al. Increased fat cell size: a major phenotype of subcutaneous white adipose tissue in non-obese individuals with type 2 diabetes. Diabetologia. 2016;59:560-70.

29. Kanda H, Tateya S, Tamori Y, Kotani K, Hiasa K, Kitazawa R, et al. MCP-1 contributes to macrophage infiltration into adipose tissue, insulin resistance, and hepatic steatosis in obesity. J Clin Investig. 2006;116:1494-505.

30. Wernstedt Asterholm I, Tao C, Morley Thomas S, Wang Qiong A, Delgado-Lopez F, Wang Zhao V, et al. Adipocyte inflammation is essential for healthy adipose tissue expansion and remodeling. Cell Metab. 2014;20:103-18.

31. Guerrero R, Vega GL, Grundy SM, Browning JD. Ethnic differences in hepatic steatosis: an insulin resistance paradox? Hepatology. 2009;49:791-801.

32. Lee HW, Kim KJ, Jung KS, Chon YE, Huh JH, Park KH, et al. The relationship between visceral obesity and hepatic steatosis measured by controlled attenuation parameter. PloS One. 2017;12: $\mathrm{e} 0187066$.

33. Cornier MA, Despres JP, Davis N, Grossniklaus DA, Klein S, Lamarche B, et al. Assessing adiposity: a scientific statement from the American Heart Association. Circulation. 2011;124:1996-2019.

34. Bjorntorp P. "Portal" adipose tissue as a generator of risk factors for cardiovascular disease and diabetes. Arteriosclerosis. 1990;10:493-6.

35. Milleo FQ, Campos AC, Santoro S, Lacombe A, Santo MA, Vicari MR, et al. Metabolic effects of an entero-omentectomy in mildly obese type 2 diabetes mellitus patients after three years. Clinics. 2011;66:1227-33.

36. Thorne A, Lonnqvist F, Apelman J, Hellers G, Arner P. A pilot study of long-term effects of a novel obesity treatment: omentectomy in connection with adjustable gastric banding. Int $\mathrm{J}$ Obes Relat Metab Disord. 2002;26:193-9.

37. Herrera MF, Pantoja JP, Velazquez-Fernandez D, Cabiedes J, Aguilar-Salinas C, Garcia-Garcia E, et al. Potential additional effect of omentectomy on metabolic syndrome, acute-phase reactants, and inflammatory mediators in grade III obese patients undergoing laparoscopic Roux-en-Y gastric bypass: a randomized trial. Diabetes Care. 2010;33:1413-8.

38. Fabbrini E, Tamboli RA, Magkos F, Marks-Shulman PA, Eckhauser AW, Richards WO, et al. Surgical removal of omental fat does not improve insulin sensitivity and cardiovascular risk factors in obese adults. Gastroenterology. 2010;139:448-55.

39. Chen Z, Yu R, Xiong Y, Du F, Zhu S. A vicious circle between insulin resistance and inflammation in nonalcoholic fatty liver disease. Lipids Health Dis. 2017;16:203. 